\title{
Estimation of the Wage and Employment Equation Model on Urban Labor Market by the Simultaneous Maximum Likelihood Method
}

\author{
Xiao $\mathrm{Du}^{1} \&$ Zhang $\mathrm{Hao}^{1}$ \\ ${ }^{1}$ Nanjing University of Aeronautics and Astronautics, China \\ Correspondence: Xiao Du, Nanjing University of Aeronautics and Astronautics, China. E-mail: \\ 705796904@qq.com
}

Received: December 9, 2016

Accepted: March 21, 2017

Online Published: March 26, 2017

doi:10.5539/ijbm.v12n4p231

URL: https://doi.org/10.5539/ijbm.v12n4p231

\begin{abstract}
This paper estimates wage and employment equation model on urban labor market by the simultaneous maximum likelihood method with CHIP-2002. The results show: human capital, personal ability and father's education background of a person will affect his/her market wage; Partner's income and preschool children have a negative effect on female employment probability but have no effect on male employment probability; Female return rate to education is $9.65 \%$ and employment elasticity to wage is 1.27 ; Male return rate to education is $5.93 \%$ and employment elasticity to wage is 0.45 ; Conventional Heckman two step procedure and Probit MLE underestimate the return rate to education and employment elasticity to wage.
\end{abstract}

Keywords: Wage equation, Employment equation, Simultaneous maximum likelihood method

\section{Introduction}

Salary system is the main indicators of the labor market development degree, which draws a lot of attention of many scholars, as the degree of marketization gets higher, the labor and wage gap reflects more and more individual differences in human capital. Currently, in China's urban labor market, solving the problem of laid-off and unemployed urban residents, and attracting unemployed to return to the labor market, have significant effect on increasing the income of urban households, and solving the problem of urban poverty .Due to the importance of wage and employment in the labor market, the study of the determinants of wage and employment has obvious practical significance.

\section{Data Description}

The use of the analysis of the data from the 2002 CHIP survey data, the sample coverage of China's East, central and West three regions of 12 provinces including nearly ten thousand families in more than 60 cities, the survey included the basic information, including personal and family income, consumption and property status, at the same time on the employment of the individual, and the individual information related to the unemployment of retirees were investigated. The investigation of the married individual jobs are mostly occupied by the working population, and taking into account the employment choice married individual behavior and unmarried individual employment choice behavior differences, this paper selects the sample as the analysis object. The analysis of married women into the sample age limit for less than 55 years old, male The sample age limit for less than 60 years of working age population, and get rid of the retired, retirement, early retirement, loss of ability to work, students, and scholars to be allocated to rise. Due to the influence of the owners of private enterprises and self-employed income by physical assets, wages and other employment occupation type form the wages of different forms, therefore, in the sample removed the occupation type for the owners of private enterprises and self-employed individuals. Since then there have been unemployed or laid-off experience wage forms and annual employment individuals may exist in the form of wage differences in the sample further remove the part of the individual. Finally, get married the number of samples of 3756 women, married men of 4314 samples are given in Table I selected in employment sample, unemployment and out of the labor market, the number of unemployed. Among them, the definition by Li Shi, Deng Qu Constant (2004) definition, namely at the end of 2002 is unemployed, layoffs, undergo (holiday), internally retired, unemployed state of the economically active population. Families of workers and other non employment definition for an exit from the labor market population. From table 1 can be seen in the selected sample of married men's employment rate was $92.74 \%$ greater than married women's employment rate $80.19 \%$. 
Table 1. Distribution of working age population

\begin{tabular}{llll}
\hline & Employment & Unemployment & Exit the labor market \\
\hline Female & 2988 & 525 & 213 \\
Male & 4001 & 300 & 13 \\
\hline
\end{tabular}

Table 2 gives the analysis of the statistical description of a variable. The individual attribute variable in the head of household, party, health for the value as a proxy variable of 0 or 1 . If the individual is headed, headed for 1 values of variables; if the individual party members, Party members from the proxy variable value is 1 ; if the individual that good physical condition compared with their peers, or better, health variables for 1; age, years of education and work experience of the units for years. Reflect the individual ability of key middle school and university admissions for value as the proxy variable of 0 or 1 . If the individual graduated from high school and graduated from key middle school, value key middle school proxy variable is 1 ; if the individual university is admitted by the national college entrance examination, college admission value proxy variables for preschool children 1 family variables is a value of 1 or 0 proxy variable Volume, if the individual has a preschool children, the value is 1 , spouse's income for the annual income of per unit; reflect the family background of the two variables are 0 or 1 of the proxy variable values. If the father or the mother had gone to college, and the value of the corresponding variable to 1 . Finally, hourly wage by individual companies in wage income divided by the number of working hours per year for get.

Table 2. Statistical description of samples

\begin{tabular}{lllll}
\hline & $\begin{array}{l}\text { Female } \\
\text { Mean value }\end{array}$ & standard deviation & $\begin{array}{l}\text { Male } \\
\text { Mean value }\end{array}$ & standard deviation \\
\hline Individual attributes: & & & & \\
Age & 41.26 & 6.63 & 44.47 & 7.31 \\
Householder & 0.33 & 0.47 & 0.69 & 0.46 \\
Party member & 0.22 & 0.41 & 0.41 & 0.49 \\
Education years & 10.91 & 2.97 & 11.40 & 3.09 \\
Healthy & 0.95 & 0.22 & 0.96 & 0.20 \\
Hands-on background & 18.78 & 9.24 & 24.07 & 8.55 \\
Personal ability: & & & & 0.44 \\
key school & 0.23 & 0.42 & 0.26 & 0.35 \\
College Admission & 0.09 & 0.28 & 0.15 & 7467.40 \\
Family situation: & & & & 0.26 \\
Spouse income & 13595.16 & 9930.78 & 9326.68 & 0.07 \\
Preschool children & 0.08 & 0.27 & & 0.25 \\
Parental education background: & & & 0.07 & 0.14 \\
Father graduated from University & 0.08 & 0.27 & 0.02 & 5.76 \\
Mother graduated from University & 0.02 & 0.15 & 6.54 & \\
Hourly wage & 5.61 & 5.38 & & \\
\hline
\end{tabular}

\section{Estimation Results}

Table 3 gives respectively the wage equation simultaneous maximum likelihood estimation and Heckman estimation results. In the two stage of the two estimation methods, most variable symbols were in line with expectations, further comparison of two methods for estimating the obtained results can be found in the two methods of individual attribute variable coefficient estimate value have the same sign, individual variable coefficient estimate difference value, the main difference estimation results shows the coefficient estimates the size of the difference. In the female wage equation, experience and experience of square coefficient estimates were significant on the two estimation methods, and a marginal decline trend, which is consistent with human capital theory; Party member variables in the estimated value of the coefficient Heckman two stage estimation is not significant, however, in the simultaneous maximum likelihood estimation method is significantly positive, indicating the Party member identity Will increase the individual's wages; key middle school and university admission coefficient estimates are significantly positive in the two estimation methods, which shows that the higher the ability of individuals, the corresponding higher wages. Father and mother graduated from the University College coefficient estimates in Heckman two stage estimation are not significant, and in the 
simultaneous maximum likelihood estimation method, the father graduated from college but has a positive impact on individual wages, without affecting the mother of university graduates, the father's education background affect the labor market performance of the individual which affect the individual market wage. The estimated value of the coefficient provinces variables significantly with different degree, that difference in regional economic environment leads to the differences of the female labor market wage level. In the male wage equation, in addition to education square estimation in the Heckman two stage method was not significant, the coefficient of other individuals attribute estimates were significant in two ways. The coefficient estimates of the provinces variables were significant, also demonstrates the regional economic differences in the environment of male Different influences of wages. Finally, the coefficient of education in a wage equation estimates to be discussed in detail. Heckman two stage estimation method of return to education of women and men were $4.43 \%$ and $4.76 \%$, the rate of return to education is higher than that of male female return rate, but the difference of only 0.33 percentage points. However, simultaneous greatly likelihood estimation of female return rate of $9.65 \%$, male education income rate was $5.93 \%$, the rate of female return rate to 3.72 percentage points higher than men return to education. This means that the Heckman two stage estimation underestimated men and women return to education, and revealed no female return rate is higher than the rate of return to education in such men the fact. Simultaneous maximum likelihood estimation and the existing research method. The result obtained is consistent with the conclusion of. Zhang and Zhao (2002) study shows that women receive education the interest rate is higher than the male education yield, and the two have the tendency to expand with the passage of time.

Table 3. Estimates of the wage equation

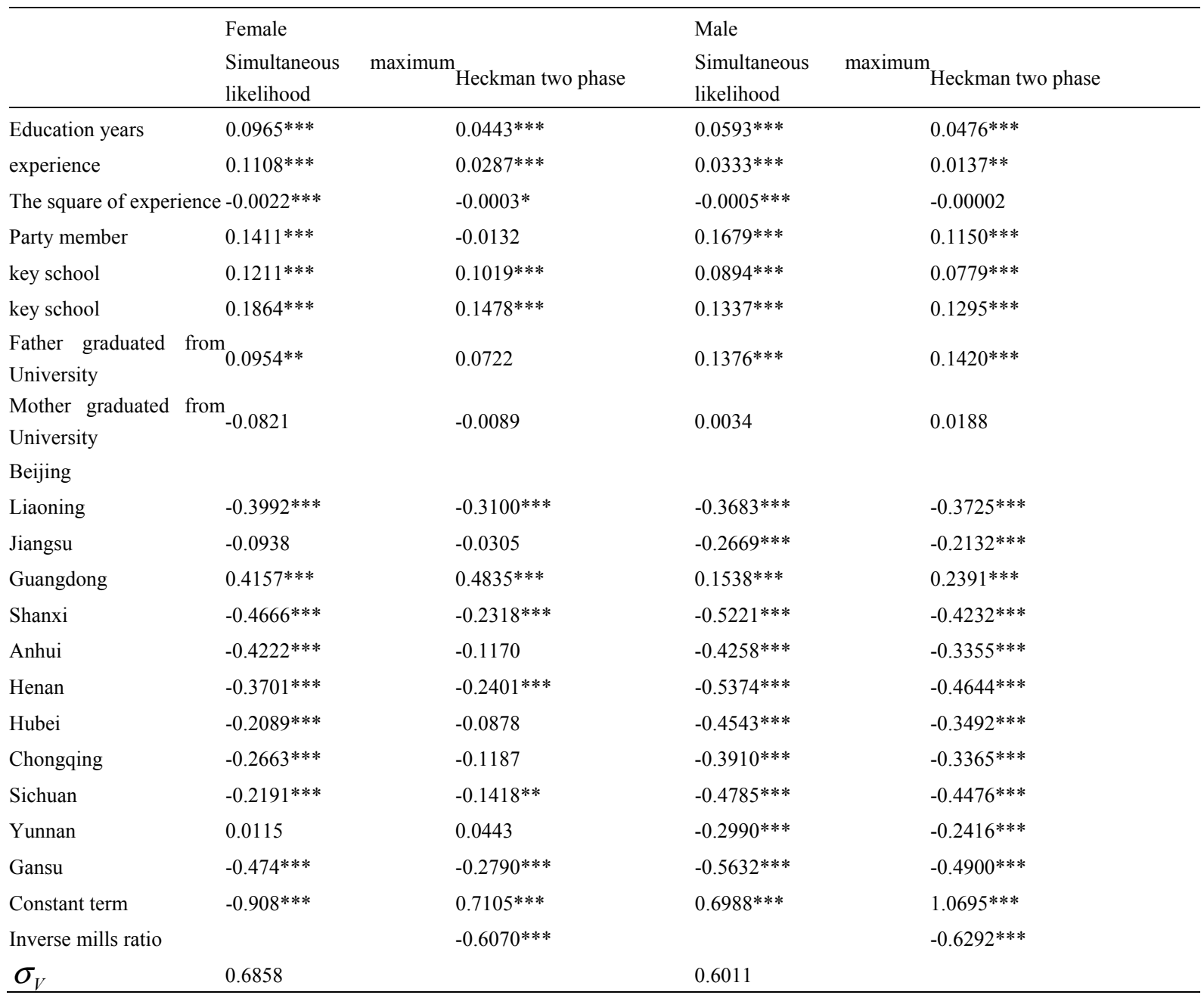

Note: $* * *, * *$ respectively the level of significant at $10 \%, 5 \%, 1 \%$, 
Table 4 gives respectively using simultaneous maximum likelihood estimation and the maximum likelihood method of Probit model estimation results of equation of employment. Comparative results of the two methods can be found, the coefficient of individual attribute variable in the estimated value of the two methods under the impact on employment probability showed the same trend and consistent with theory the expected differences, the results of the two approaches is mainly reflected in the coefficient estimates the size of the difference. In the employment of women in the equation, with the increase of age, the probability of employment showed a decreasing trend, which is consistent with the theory of life cycle; individual households, the probability of employment will increase; life education of Party members and reflects the individual's human capital endowment, individual party members, education is higher, the greater the probability of employment; health can promote individual employment; when using the Probit model, the spouse income coefficient estimation Value is not significant, but when using simultaneous maximum likelihood estimation, the spouse's income coefficient estimate value is significantly negative, indicating that spouse's income decreases with the increasing of the probability of female employment and income effect is negative; two estimation methods, coefficient of preschool children estimation values are at the $10 \%$ level of significant and illustrate with preschool children increased women's household labor burden, tend to reduce the probability of employment of women. Provinces proxy variable coefficient estimates of the values in the two estimation methods have different degrees of saliency. Explain the difference of regional economic environment will affect women's employment probability. In two estimation methods, the male employment equation except spouse income and preschool children the number of other individual attribute variables on the probability of employment and income of women of the same, the coefficient of preschool children and spouse estimates were not significant, indicating the impact of family factors of male employment probability is small. The proxy variable of the estimated coefficient of provinces with the same value significantly different degree in two kinds of estimation methods, illustrate the differences of the regional economic environment will affect the employment probability of male individuals. Finally, focus on the coefficient of the logarithm of wage hour estimates. In the two method, the coefficient of wages of female and male employment equation estimates are logarithmic hours, that increase the probability of employment of women and men with the market wage rate increased, consistent with the theoretical expectations of the search and matching model. Either female or male employment By using the Probit model equation, the logarithm of hourly wage coefficient estimates were less than the simultaneous maximum likelihood estimation method to get the coefficient estimates, this shows that the employment equation using the Probit model underestimate the impact of market wage on individual probability of employment. On the basis of simultaneous maximum likelihood estimation method in the logarithm of hourly wage coefficient estimates employment, wage elasticity calculation of women and men in the sample mean at 1.27 and 0.45 . respectively the majority of foreign experience on labor supply, labor supply elasticity of labor supply elasticity of women than men, and the labor force participation elasticity is greater than the flexible working time (Blundell and Macurdy, 1999), this study did not consider the other on the one hand, labor supply, working hours, but from the point of view of employment, the employment wage elasticity of employment wage elasticity of women than men, it is consistent with the conclusion obtained from the foreign research.

Table 4. Estimates of the employment equation

\begin{tabular}{|c|c|c|c|c|}
\hline & \multicolumn{2}{|l|}{ Female } & \multicolumn{2}{|l|}{ Male } \\
\hline & $\begin{array}{l}\text { Simultaneous } \\
\text { likelihood }\end{array}$ & maximum $_{\text {Probit }}$ & $\begin{array}{l}\text { Simultaneous } \\
\text { likelihood }\end{array}$ & maximum $_{\text {Probit }}$ \\
\hline $\begin{array}{l}\text { Logarithmic } \\
\text { wage }\end{array}$ & hourly $_{1.0198 * * *}$ & $0.3418 * * *$ & $0.4228 * * *$ & $0.1282 * *$ \\
\hline Age & $-0.0395 * * *$ & $-0.0316 * * *$ & $-0.0468 * * *$ & $-0.0456^{* * *}$ \\
\hline A householder & $0.3297 * * *$ & $0.4474 * * *$ & $0.1843 * * *$ & $0.2068 * * *$ \\
\hline Party member & $0.6340 * * *$ & $0.6820 * * *$ & $0.3053 * * *$ & $0.3536 * * *$ \\
\hline Education years & $0.0407 * * *$ & $0.1073 * * *$ & $0.0279 * *$ & $0.0452 * * *$ \\
\hline Health & $0.3897 * * *$ & $0.3381 * * *$ & $0.7404 * * *$ & $0.7536^{* * *}$ \\
\hline Spouse income & $-0.1245 * * *$ & -0.0385 & 0.0034 & 0.0502 \\
\hline
\end{tabular}




\begin{tabular}{|c|c|c|c|c|}
\hline Preschool children & $-0.1087^{*}$ & $-0.2036^{*}$ & 0.2378 & 0.2088 \\
\hline \multicolumn{5}{|l|}{ Beijing } \\
\hline Liaoning & $-0.3690 *$ & $-0.3500 * *$ & 0.0662 & 0.0008 \\
\hline Jiangsu & $-0.6286 * * *$ & $-0.4065^{* * *}$ & $-0.4296^{* *}$ & $-0.4553 * * *$ \\
\hline Guangdong & $-1.1070 * * *$ & $-0.6314 * * *$ & $-0.6925^{* * *}$ & $-0.6189^{* * *}$ \\
\hline Shanxi & $-0.6469 * * *$ & $-0.8250 * * *$ & $-0.565^{* * *}$ & $-0.6864 * * *$ \\
\hline Anhui & $-1.0517 * * *$ & $-0.9736^{* * *}$ & $-0.542 * * *$ & $-0.6011 * * *$ \\
\hline Henan & $-0.7209 * * *$ & $-0.6403 * * *$ & $-0.4948 * * *$ & $-0.5851 * * *$ \\
\hline Hubei & $-0.9159 * * *$ & $-0.7447 * * *$ & $-0.6006^{* * *}$ & $-0.6698 * * *$ \\
\hline Chongqing & $-0.8214 * * *$ & $-0.6718^{* * *}$ & -0.3081 & $-0.3539^{* *}$ \\
\hline Sichuan & $-0.6297 * * *$ & $-0.5154 * * *$ & -0.1094 & -0.1997 \\
\hline Yunnan & $-0.6989 * * *$ & $-0.4154 * *$ & $-0.4049 * *$ & $-0.4306^{* *}$ \\
\hline Gansu & $-0.5542 * * *$ & $-0.7137 * * *$ & $-0.4165^{* *}$ & $-0.5486^{* * *}$ \\
\hline Constant term & $1.4911^{* * *}$ & $0.7281 * *$ & $2.1083^{* * *}$ & $2.2475^{* * *}$ \\
\hline
\end{tabular}

Note: $* * *, * * *$, respectively, which indicated that in $10 \%, 5 \%$ and $1 \%$ level significantly. In using probit model to estimate the employment equation, employment of the individual real log hourly wage and employment predictions of individual log hourly wage as the $\log$ hourly wage variable. Among them, the employment of the individual log hourly wage prediction value by Heckman two stage estimation method.

\section{Conclusion}

This paper uses simultaneous maximum likelihood estimation for simultaneous estimation of the wage equation and the equation of employment in the urban labor market method, and compared with the traditional method of estimation of the wage equation and Probit model to estimate the employment equation results were estimated using the Heckman two phase. The wage equation extends the basic Mincer equation set the embodiment of personal ability and family background variables. Simultaneous maximum likelihood estimation method of the wage equation shows that wage differences in human capital for the individual influence, and conform to the theory of human capital is expected to have positive influence on individual ability of individual wages, higher ability, the higher the level of individual wages wages, father's education background of individual impact, father's education background is higher, individual wages higher. Simultaneous maximum likelihood estimation Meter and Heckman two stage estimation method has been the main differences between the wage equation is the education coefficient estimates the difference, that is the difference between the rate of return to education. Heckman two stage estimation method in the male and female education yields were $4.43 \%$ and $4.76 \%$, slightly higher than the rate of return to education of male female education income rate, simultaneous maximum likelihood estimation method of female return rate of $9.65 \%$, male education income rate was $5.93 \%$, the rate of female return rate to 3.72 percentage points higher than men return to education. This means that the Heckman two stage estimation underestimated men and women return to education, and revealed no female return rate is higher than the rate of return to education in men the simultaneous maximum likelihood estimation. The coefficient of individual attribute variables in the equations of employment income method estimates were consistent with the theoretical expectations, spouse income and employment of women in school-age children Equation significantly. The probability of employment for women with negative impact and probability of employment for the men had no effect, suggesting that male employment probability is affected by family factors influence smaller. Simultaneous maximum likelihood estimation method to get the employment equation, the coefficients of the log hourly wage estimation value is greater than the probit model to obtain the estimated value, probit model underestimates the effects of market wage on employment probability. According to the coefficients of the equations are employed in log hourly wage, employment and the wage elasticity estimate value is calculated at the sample mean, the female wage employment elasticity 1.27 , male wage employment elasticity is 0.45 , the female wage employment elasticity is greater than male wage employment elasticity.

Due to the female education income rate and wage employment elasticity were higher than that in male, and female employment income can to narrow the household income gap (Ding, Sai, Xiao Yuan Dong, Li Shi, 2007). Re employment training active labour market policies will be able to increase the individual's human capital, promoting employment and withdraw from the labor market individual employment, especially to promote the employment of women, increasing women's employment income and to alleviate urban income inequality, reduce urban poverty has obvious effect. 


\section{References}

Blundell, B. R., \& Macurdy, T. (2015). Labor Supply of Men: A Review of Alternative Approaches. Handbook of Labor.

Blundell, R., \& Smith, R. J. (1994). Coherency and estimation in simultaneous models with censored or qualitative dependent variables. Journal of Econometrics, 64(1-2), 355-373.

Griliches, Z. (1977). Estimating the returns to schooling. Econometrica.

Schultz, B. T. W. (2015). Education, investments and returns. In H.Chenery and T. N. Srinavasan (Eds.), Handbook of Development Economics.

Gronau, R. (1973). Wage Comparisons-A Selectivity Bias (Vol. 82, pp. 1119-1143). National Bureau of Economic Research, Inc.

Heckman, J. (1976). The Common Structure of Statistical Models for Truncation. Sample Selection and Limited Dependent Variables and a Simple Estimator for such Models. Annals of Economic and Social Measurement, 475-492.

\section{Copyrights}

Copyright for this article is retained by the author(s), with first publication rights granted to the journal.

This is an open-access article distributed under the terms and conditions of the Creative Commons Attribution license (http://creativecommons.org/licenses/by/4.0/). 